\title{
The Women of Karbala. Ritual Performance and Symbolic Discourses in Modern Shi'i Islam. Austin. University of Texas Press, 2005, 297 p.
}

\section{Azadeh Kian-Thiébaut}

\section{(2) OpenEdition}

1 Journals

Édition électronique

URL : http://journals.openedition.org/abstractairanica/11042

DOI : 10.4000/abstractairanica. 11042

ISSN : 1961-960X

Éditeur :

CNRS (UMR 7528 Mondes iraniens et indiens), Éditions de l'IFRI

\section{Édition imprimée}

Date de publication : 15 mai 2007

ISSN : 0240-8910

Référence électronique

Azadeh Kian-Thiébaut, «The Women of Karbala. Ritual Performance and Symbolic Discourses in Modern Shi'i Islam. Austin. University of Texas Press, 2005, 297 p. », Abstracta Iranica [En ligne], Volume 28 | 2007, document 506, mis en ligne le 18 septembre 2007, consulté le 25 septembre 2020. URL : http://journals.openedition.org/abstractairanica/11042 ; DOI : https://doi.org/10.4000/ abstractairanica. 11042

Ce document a été généré automatiquement le 25 septembre 2020

Tous droits réservés 


\title{
The Women of Karbala. Ritual Performance and Symbolic Discourses in Modern Shi'i Islam. Austin. University of Texas Press, 2005, 297 p.
}

\author{
Azadeh Kian-Thiébaut
}

1 Cet ouvrage collectif inédit réunit plusieurs spécialistes du chi'isme avec des contributions sur les pratiques, rituels et symboles chi'ites en Iran, en Irak, au Pakistan, au Liban et aux États-Unis. Après un aperçu de l'émergence et du développement historique des rites et des symboles chi'ites, l'ouvrage présente et analyse le rôle des femmes souvent absentes dans les travaux des historiens occidentaux, ces derniers ayant surtout souligné la dimension politique de l'imam Ḥoseyn en tant que symbole de martyre et de rébellion. Quant aux historiens du contemporain, qui ont étudié les symboles de Karbalā, ils se sont centrés sur le champ de bataille et ont ainsi privilégié les martyrs hommes, au détriment des figures féminines du récit fondateur (Zeynab, la sœur de l'imam Ḥoseyn, ou Fāțeme, sa mère et son éducatrice). De même, les recherches sur les rituels de moharram (le mois du deuil) se sont penchées presque exclusivement sur la procession et la flagellation des hommes, omettant ainsi la participation des femmes à ces rituels.

2 Les contributions dans cet ouvrage montrent que les symboles chi'ites ont été utilisés pour définir le comportement féminin idéal. Aussi, certains symboles sont sexués tandis que d'autres sont neutres. Ils ont été utilisés pour renforcer la différence entre les genres tout en soulignant la centralité des femmes dans le répertoire symbolique du chi'isme. S'il est vrai que les symboles et rituels ont été utilisés afin de limiter les activités et les rôles sociaux des femmes, ils ont aussi servi à leur donner du pouvoir et à promouvoir les identités féminines. Bien que les composantes des croyances et des pratiques chi'ites soient à vocation universelle, les expériences religieuses des femmes 
varient selon les préférences personnelles, les interprétations religieuses, les pratiques culturelles populaires, les normes des interactions sexuées (ségrégation plus ou moins grande), les coutumes régionales, le niveau d'éducation ou les origines sociales.

3 Negar Mottahedeh analyse les dynamiques du genre dans le tatziye sous les Qâjârs. Kamran Scot Aghaie aborde les dynamiques du genre dans les symboles et les rituels chi'ites sous la même dynastie. Ingred Flaskerud présente les rituels religieux des femmes à Šīrāz aujourd'hui. Faegeh Shirazi analyse diverses représentations des caractères féminins dans les chants, les élégies et les slogans dans les rituels populaires en Iran. Peter J. Chelkowski examine les représentations visuelles des grandes figures féminines, en particulier de Zeynab, la sœur de Ḥoseyn, et de Šahrbānū, son épouse iranienne, dans les drames religieux chi'ites. Shemeen Burney Abbas analyse la façon dont les thèmes sexués sont exprimés à travers le récit de la voix de Sakine dans les rituels du deuil au Pakistan. Syed Akbar Hyder recense les diverses façons dont Zeynab est représentée dans les poèmes modernes et les élégies en urdu. Rehana Ghadially étudie les Ismâ'ili dans la communauté Bohra de l'Inde où les rituels publics sont mixtes; mais elle montre que les rituels réservés aux femmes donnent à celles-ci un sentiment plus fort de leur centralité dans la foi chi'ite; elle analyse enfin les tensions entre les normes sociales patriarcales et les aspects émancipateurs de la participation des femmes à ces rituels. Mary Elaine Hegland compare deux principales communautés chi'ites immigrées aux Etats-Unis, les Iraniens et les Sudasiatiques, et présente les variations dans leurs pratiques religieuses, variations qu'elle attribue principalement à leurs origines sociales et économiques différentes. Elizabeth Warnock Fernea et Basima Q. Bazirgan remettent en question la dichotomie privé-public, assimilée à une dichotomie entre ce qu'on a appelé le "monde des femmes" et le "monde des hommes " dans les sociétés musulmanes; or, soulignent-elles, les hommes et les femmes participent ensemble aux rituels publics. Lara Z. Deeb analyse les récents changements dans les rituels chi'ites au Liban suscités par l'urbanisation, la modernisation et la montée politique des partis chi'ites comme Amal ou Hezbollah ; aux côtés des rituels traditionnels, une nouvelle modalité de rituels a émergé ces dernières années sous l'influence de l'Iran : ainsi, Zeynab est considérée comme un modèle plus authentique pour les femmes qui s'impliquent de plus en plus dans les activités sociales et politiques.

INDEX

Thèmes : 16.1. Iran

\section{AUTEURS}

AZADEH KIAN-THIÉBAUT

Université Paris VIII / Mondes iranien et indien 